\title{
Intratumoral heterogeneity in a minority of ovarian low-grade serous carcinomas
}

\author{
Alicia A Tone ${ }^{1,2,3 \dagger}$, Melissa K McConechy ${ }^{1,2+}$, Winnie Yang ${ }^{2}$, Jiarui Ding ${ }^{4}$, Stephen Yip ${ }^{1,2}$, Esther Kong ${ }^{2}$, \\ Kwong-Kwok Wong ${ }^{5}$, David M Gershenson ${ }^{5}$, Helen Mackay ${ }^{6}$, Sohrab Shah ${ }^{4}$, Blake Gilks ${ }^{1}$, Anna V Tinker², \\ Blaise Clarke ${ }^{7}$, Jessica N McAlpine ${ }^{2,8}$ and David Huntsman ${ }^{1,2^{*}}$
}

\begin{abstract}
Background: Ovarian low-grade serous carcinoma (LGSC) has fewer mutations than ovarian high-grade serous carcinoma (HGSC) and a less aggressive clinical course. However, an overwhelming majority of LGSC patients do not respond to conventional chemotherapy resulting in a poor long-term prognosis comparable to women diagnosed with HGSC. KRAS and BRAF mutations are common in LGSC, leading to clinical trials targeting the MAPK pathway. We assessed the stability of targetable somatic mutations over space and/or time in LGSC, with a view to inform stratified treatment strategies and clinical trial design.
\end{abstract}

Methods: Eleven LGSC cases with primary and recurrent paired samples were identified (stage IIB-IV). Tumor DNA was isolated from 1-4 formalin-fixed paraffin-embedded tumor blocks from both the primary and recurrence $(n=37$ tumor and $n=7$ normal samples). Mutational analysis was performed using the lon Torrent AmpliSeq ${ }^{\text {TM }}$ Cancer Panel, with targeted validation using Fluidigm-MiSeq, Sanger sequencing and/or Raindance Raindrop digital PCR.

Results: KRAS (3/11), BRAF (2/11) and/or NRAS (1/11) mutations were identified in five unique cases. A novel, non-synonymous mutation in SMAD4 was observed in one case. No somatic mutations were detected in the remaining six cases. In two cases with a single matched primary and recurrent sample, two KRAS hotspot mutations (G12V, G12R) were both stable over time. In three cases with multiple samplings from both the primary and recurrent surgery some mutations (NRAS Q61R, BRAF V600E, SMAD4 R361G) were stable across all samples, while others (KRAS G12V, BRAF G469V) were unstable.

Conclusions: Overall, the majority of cases with detectable somatic mutations showed mutational stability over space and time while one of five cases showed both temporal and spatial mutational instability in presumed drivers of disease. Investigation of additional cases is required to confirm whether mutational heterogeneity in a minority of LGSC is a general phenomenon that should be factored into the design of clinical trials and stratified treatment for this patient population.

Keywords: Heterogeneity, Low-grade cancer, Ovarian serous carcinoma, Mutation, KRAS, BRAF, NRAS, SMAD4

\section{Background}

In comparison to the more commonly occurring high-grade serous carcinomas (HGSC), ovarian low-grade serous carcinomas (LGSC) are characterized by a younger age at onset, lower mitotic rate and longer median overall survival

\footnotetext{
* Correspondence: dhuntsma@bccancer.bc.ca

${ }^{\dagger}$ Equal contributors

'Department of Pathology and Laboratory Medicine, University of British

Columbia, Vancouver, BC, Canada

${ }^{2}$ BC Cancer Agency, Room 3427, 600 West 10th Avenue, Vancouver, BC, Canada

Full list of author information is available at the end of the article
}

[1-6]. Whereas the vast majority (80\%) of patients with HGSC are responsive to platinum-based chemotherapy, patients with LGSC are highly resistant to treatment in the neoadjuvant, adjuvant and recurrent setting, with response rates of $4-5 \%[1,7,8]$. Women diagnosed with LGSC typically experience multiple recurrences over a protracted clinical course before ultimately dying of their disease, with an associated 10-year survival rate of $<50 \%$ [2]. This suggests that despite having a less aggressive clinical course, women with LGSC have a poor long-term prognosis similar to HGSC patients; this is highlighted by a recent

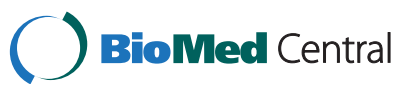

(c) 2014 Tone et al.; licensee BioMed Central. This is an Open Access article distributed under the terms of the Creative Commons Attribution License (http://creativecommons.org/licenses/by/4.0), which permits unrestricted use, distribution, and reproduction in any medium, provided the original work is properly credited. The Creative Commons Public Domain Dedication waiver (http://creativecommons.org/publicdomain/zero/1.0/) applies to the data made available in this article unless otherwise stated. 
study reporting a similar hazard ratio for death in LGSC and HGSC patients with measurable residual disease after adjusting for additional variables [9].

In an effort to identify potential molecular targets, limited mutational studies in primary or recurrent LGSC samples have revealed an overall low mutation frequency, with exome sequencing by Jones et al. showing an average of 10 validated somatic mutations (or 7.5 somatic non-synonymous or splice site mutations) per tumor [10]. The mitogen-activated kinase (MAPK) pathway is most frequently mutated [11], with $19-35 \%$ of cases containing a KRAS mutation and $2-33 \%$ containing a BRAF mutation [3,10,12-14]. KRAS and BRAF mutations are also frequently detected in serous borderline tumors (SBT), the histologic precursor to invasive LGSC [5,6,11,15-17].

The prevalence of KRAS/BRAF mutations in LGSC has resulted in clinical trials of inhibitors of MAP kinase kinase (MEK1/2), which lies immediately downstream of BRAF and upstream of ERK1/2 in the MAPK pathway $[18,19]$. Previous studies have reported profound growth inhibition and apoptosis in ovarian cancer cells with mutated but not wildtype KRAS or BRAF upon treatment with CI-1040 [20] in tissue culture and xenograft studies $[19,21]$, suggesting that mutation status predicts sensitivity to MEK inhibition. A recent phase II study of selumetinib, another small molecular inhibitor of MEK1/2, in women with recurrent ovarian/peritoneal LGSC has shown an objective $15 \%$ response rate despite heavy pre-treatment; however patient response does not appear to be correlated with KRAS/BRAF mutation status [18]. The mutation status of the patients in this trial was based solely on a single sample of LGSC; most were obtained from the primary tumor and a small percentage were obtained from the recurrent tumor. In this study we aimed to assess the stability of targetable mutations over space and/or time by targeted sequence analysis of one or more tumor samples from both the primary and recurrence, to inform future clinical trial design. Herein we report our findings of mutational stability in the majority of cases, as well as remarkable instability in one case of ovarian LGSC, in presumed drivers of disease $K R A S$ and $B R A F$. If validated in more cases this could impact clinical trial design for this patient population in the future.

\section{Methods}

\section{Study cases}

A total of 11 cases of LGSC with matched primary and recurrent samples available were identified from the University Health Network in Toronto, Ontario ("UHN", n=3), MD Anderson Cancer Center in Houston, Texas ("MDACC", $\mathrm{n}=3$ ) and the $\mathrm{BC}$ Cancer Agency in Vancouver, British Columbia ("BCCA", $\mathrm{n}=5$ ). The stage breakdown included: $\operatorname{IIB}(n=1)$, IIIB $(n=3)$, IIIC $(n=6)$ and IV $(n=1)$. Research ethics approval was obtained from each site (UBC BCCA Research Ethics Board, University Health Network Research Ethics Board and The University of Texas MD Anderson Cancer Center Institutional Review Board). All patients provided written informed consent to have their tissue samples used for research purposes, including genomic studies. Written informed consent was obtained from every patient for publication of the specific clinical details included within this research article and any accompanying images. However, potentially identifying information such as date of diagnosis have been removed to protect privacy. Upon inclusion in the study, all formalin-fixed paraffin-embedded (FFPE) sections chosen for sequence analysis were subjected to secondary pathologic review (B.G.). Two of eleven cases originally presented as a SBT, and recurred as invasive LGSC. Nine patients received adjuvant treatment following diagnosis, including six treated with combined carboplatin/paclitaxel.

A total of 37 tumor samples (from either FFPE blocks [BCCA] or unstained sections [MDACC/UHN]) were included for analysis. At least one sampling from both the primary and recurrent setting were included for each case, with H\&E-guided macrodissection used to isolate tumor from adjacent stromal cells. Tumor cellularity achieved following macrodissection was estimated at a median of 80\% (range 50-95\%) and was comparable among samples obtained from the same case. Normal samples were available for 7 cases (6 matched normal tissue, 1 buffy coat). We were also able to obtain a fresh blood sample from one BCCA study patient for extraction of circulating tumor DNA ("ctDNA"). Summary information for all study cases is included in Table 1, with more detailed information on tumor sites and normal samples used in Additional file 1 and case images in Additional files 2, 3, 4, $5,6,7,8,9,10,11$ and 12 .

\section{DNA extraction}

Tumor and normal DNA was extracted from FFPE blocks/unstained sections (see Additional file 13 for supplemental methods). For extraction of ctDNA, whole blood was collected in EDTA tubes then centrifuged at $2,500 \mathrm{rpm}$ for $15 \mathrm{~min}$. Plasma was then stored at $-80 \mathrm{C}$ in 1-2 mL aliquots, followed by extraction of plasma ctDNA using the Qiagen Circulating Nucleic Acid kit as per manufacturer's protocol. ctDNA was then eluted in 30uL of Buffer AVE.

\section{Ion torrent AmpliSeq cancer hotspot sequencing}

The Ion Torrent AmpliSeq ${ }^{\mathrm{TM}}$ Cancer Hotspot Panel Version 1 (Life Technologies, Grand Island/NY/USA) [22] was used to prepare sequencing libraries from all tumor DNA, normal DNA and plasma ctDNA as per manufacturer's protocols (see Additional file 13 for methodological details and Additional file 14 for a comprehensive 
Table 1 Summary of study cases

\begin{tabular}{|c|c|c|c|c|c|c|c|c|}
\hline Case & Source & Age & $\begin{array}{l}\text { \# Tumor } \\
\text { samples }\end{array}$ & Stage & $\begin{array}{l}\text { Primary tumor } \\
\text { samples }\end{array}$ & Intervening $\mathrm{Tx} / \mathrm{s}$ & $\begin{array}{c}\text { Recurrent samples } \\
\text { (***Time to recurrence) }\end{array}$ & $\begin{array}{l}* * * \text { Time to/Status } \\
\text { last followup }\end{array}$ \\
\hline LGSC-2 & UHN & 57 & 2 & IIIC & $2-P^{*}$ & Carboplatin/paclitaxel & $2-\mathrm{R}(46 \mathrm{mo})$ & $86 \mathrm{mo} / \mathrm{AWD}$ \\
\hline LGSC-3 & UHN & 51 & 2 & IIIC & $3-P^{*}$ & Carboplatin/paclitaxel & $3-\mathrm{R}(17 \mathrm{mo})$ & $19 \mathrm{mo} / \mathrm{AWD}$ \\
\hline LGSC-4 & UHN & 66 & 3 & $\| \mathrm{IIB}$ & $4-P$ & Carboplatin & 4-R1 (25 mo), 4-R2 (45 mo) & $60 \mathrm{mo} / \mathrm{DOD}$ \\
\hline LGSC-5 & MDACC & 51 & 2 & $I I I C$ & $5-P$ & Carboplatin/paclitaxel, letrozole & 5-R (37 mo) & $53 \mathrm{mo} / \mathrm{DOD}$ \\
\hline LGSC-6 & MDACC & 41 & 2 & IIIC & $6-P$ & Carboplatin/paclitaxel & $6-\mathrm{R}(24 \mathrm{mo})$ & $87 \mathrm{mo} / \mathrm{DOD}$ \\
\hline LGSC-8 & MDACC & 33 & 2 & $I I I C$ & $8-P$ & Cisplatin/cyclophos-phamide & 8-R (7 mo) & $12 \mathrm{mo} / \mathrm{DOD}$ \\
\hline LGSC-9** & BCCA & 51 & 6 & $\| \mathrm{B}$ & 9-P1, P2, P3* & No treatment & 9-R1, R2, R3 (100 mo) & $141 \mathrm{mo} / \mathrm{DOD}$ \\
\hline LGSC-10 & BCCA & 57 & 8 & IV & 10-P1, P2, P3, P4* & $\begin{array}{l}\text { Carboplatin/paclitaxel, } \\
\text { radiation }\end{array}$ & 10-R1, R2, R3, R4 (45 mo) & $62 \mathrm{mo} / \mathrm{DOD}$ \\
\hline LGSC-11** & BCCA & 62 & 2 & $\mathrm{IIIC}$ & $11-P^{*}$ & No treatment & 11-R (156 mo) & $180 \mathrm{mo} / \mathrm{DOD}$ \\
\hline LGSC-12 & BCCA & 57 & 6 & $\| B$ & $12-P 1, P 2, P 3, P 4 *$ & $\begin{array}{l}\text { Etoposide, tamoxifen, } \\
\text { anastrozole }\end{array}$ & 12-R1, R2 (18 mo) & $53 \mathrm{mo} / \mathrm{DOD}$ \\
\hline LGSC-13 & BCCA & 58 & 2 & $\| \mathrm{B}$ & $13-P^{*}$ & Carboplatin/paclitaxel & 13-R (46 mo) & $59 \mathrm{mo} / \mathrm{DOD}$ \\
\hline $\begin{array}{l}\text { Mean } \\
\text { (Total) }\end{array}$ & & 53.1 & $3.4(37)$ & & & & & \\
\hline
\end{tabular}

${ }^{*}$ normal sample also available; ${ }^{* *}$ initial diagnosis of SBT; ${ }^{* * *}$ time in months since diagnosis.

Abbreviations: $\mathrm{AWD}=$ alive with disease, $\mathrm{DOD}=$ dead of disease.

list of genes and mutations included on the AmpliSeq panel). A list of predicted variants was generated for each sample using the built-in AmpliSeq Cancer Variant Caller following each run. Upon completion of all samples, we performed a separate bioinformatics analysis. Sequence reads were aligned to the human reference sequence (UCSC hg19) using the BWA SW algorithm (v0.6.1) [23] with default parameters. Single nucleotide variants (SNV) were called using mutationSeq [24], a feature-based method to filter out technical artifacts. We used a variant probability threshold of 0.5 to nominate SNVs. Variants predicted in the pooled normal data were considered as germline mutations and were removed.

Variants were selected for targeted validation by MiSeq in all samples according to the following selection criteria: [1] either somatic (variant not found in corresponding normal sample if available) or predicted somatic (for cases with no corresponding normal - variant not found in dbSNP or in normal samples from other cases), [2] non-synonymous and [3] predicted functional impact according to MutationAssessor [25], a method to predict the functional impact of missense mutations on protein products based on evolutionary conservation of amino acid residues in multi-sequence alignment of homologous protein sequences.

\section{Fluidigm-MiSeq targeted sequencing validation}

Variants identified by Ion Torrent AmpliSeq sequencing results were verified by validation sequencing using the Fluidigm 48X48 AccessArray amplification (Fluidigm, San Francisco/CA/USA) coupled with the Illumina MiSeq personal sequencer (Illumina Inc, San Diego/CA/USA) (see Additional file 13). Sequence reads were aligned using the mem algorithm of BWA v0.7.4 [26] to a reference database containing only the targeted loci. We inferred the presence/absence of the targeted variants using a Binomial exact test. In the context of this analysis, a somatic mutation was considered to be "validated" if: [1] both tumor and normal data had a minimum of 50 reads covering the targeted position, [2] the Binomial exact test result (Benjamini Hochberg adjusted p-value) for the tumor was $<0.01,[3]$ the Binomial exact test result (Benjamini Hochberg adjusted p-value) for the normal was $>=0.01$, and [4] the proportion of reads indicating the variant in the tumor was $\geq 5 \%$. For the cases without a normal control, the validated variants also shown in the pooled normal data were considered as germline mutations and were removed. All mutations were visually confirmed using the Integrative Genomics Viewer (Broad Institute, Cambridge/MA/USA).

\section{Sanger sequencing}

Sanger sequencing was used to confirm select high allelic fraction mutations, using methods previously described [27]. Primer sequences are listed in Additional file 15.

\section{Raindance raindrop digital PCR assay}

Custom TaqMan SNP Genotyping assays (Life Technologies, CA/USA) were used as primer/probes (40X) to confirm low allelic fraction mutations using the Raindance Raindrop digital PCR assay (Raindance, Billerica/MA/USA). Sequences for primers are shown in Additional file 16. Digital PCR assays were performed as per manufacturer's protocols (see Additional file 13). 


\section{Definition of true positive mutations}

Only those mutations that were detected by at least two independent technologies were considered "true positives" and were included in intra-patient comparisons.

\section{Results}

\section{Overall mutational landscape of LGSC study cases}

Following initial screening by Ion Torrent and validation by MiSeq, Sanger and/or digital PCR, very few "true positive" mutations were observed overall, with only 7 mutations detected among 5 of 11 cases. No somatic mutations were observed in cases LGSC-2, LGSC-4, LGSC-5 and LGSC-13, whereas predicted mutations in cases LGSC- 6 and LGSC-8 were only detected by one of the sequencing platforms used. True positives included KRAS mutations in 3 cases $(\mathrm{n}=2 \mathrm{G} 12 \mathrm{~V}$ and $\mathrm{n}=1$ G12R), BRAF mutations in 2 cases ( $\mathrm{n}=1 \mathrm{~V} 600 \mathrm{E}$ and $\mathrm{n}=1 \mathrm{G} 469 \mathrm{~V})$, and NRAS (Q61R) and SMAD4 (R361G) mutations in one case each. The average allelic fraction of each of these mutations in individual samples as determined by Ion Torrent and MiSeq is shown in Figure 1 (see Additional file 17 and Additional file 18 for data from each platform). Mutational patterns over time/space will be discussed for individual cases in the following sections.

\section{Mutational stability over time}

Two cases with one primary and recurrent sample each (LGSC-3 and LGSC-11) were used to assess temporal stability of confirmed somatic mutations (see Figure 2A-B for overview of clinical course).

LGSC-3 is from a 51 year old patient diagnosed with bilateral ovarian LGSC with extensive extra-ovarian involvement, stage IIIC (described in Additional file 1). This patient received adjuvant carboplatin/paclitaxel prior to disease recurrence 17 months after primary diagnosis. At last follow-up (19 months post-diagnosis) the patient was alive with disease. Sequencing analysis discovered a KRAS hotspot mutation (chr12:25,398,284C > A, G12V) at a similar allelic fraction of $\sim 50 \%$ (range $48-53 \%$ ) in the primary and recurrent samples, suggesting that this was a stable feature in this tumor (see Additional file 19 for confirmation by Sanger).

LGSC-11 is from a 62 year old patient diagnosed with stage IIIC SBT of the left ovary, with ovarian surface involvement and non-invasive implants. This patient received no additional treatment, recurred with metastatic LGSC 13 years later and died of disease 15 years postdiagnosis. The tumor was found to have a KRAS hotspot mutation (chr12:25,398,285C > G, G12R) at a similar allelic fraction in the primary (SBT, 57\%) and recurrent (LGSC, 44\%) sample by both Ion Torrent and MiSeq.

\section{Mutational stability over space and time}

Multiple samplings from both the primary and recurrent setting from three cases (LGSC-9, LGSC-10 and LGSC-12) were used to assess the spatial and temporal stability of features (see Figure 2C-E for overview of clinical course).

LGSC-9 is from a 51 year old patient diagnosed with stage IIIB SBT of the right ovary with noninvasive implants. No additional treatment was given after primary surgery. More than 8 years (100 months) following initial diagnosis, there was tumor recurrence involving the ovary and rectosigmoid, demonstrating malignant transformation to LGSC with borderline features. This was treated by complete surgical resection. A second recurrence (sigmoid mass) of LGSC occurred 23 months later. At this time she was treated with anastrozole (a nonsteroidal aromatase-inhibitor [28]), and died of disease 141 months following initial diagnosis. Sequencing analysis revealed a somatic, non-synonymous mutation in NRAS (chr1:115,256,529 $\mathrm{T}>\mathrm{C}, \mathrm{Q} 61 \mathrm{R})$ at a comparable allele fraction (mean of $50 \%$, range $40-73 \%$ ) in all six

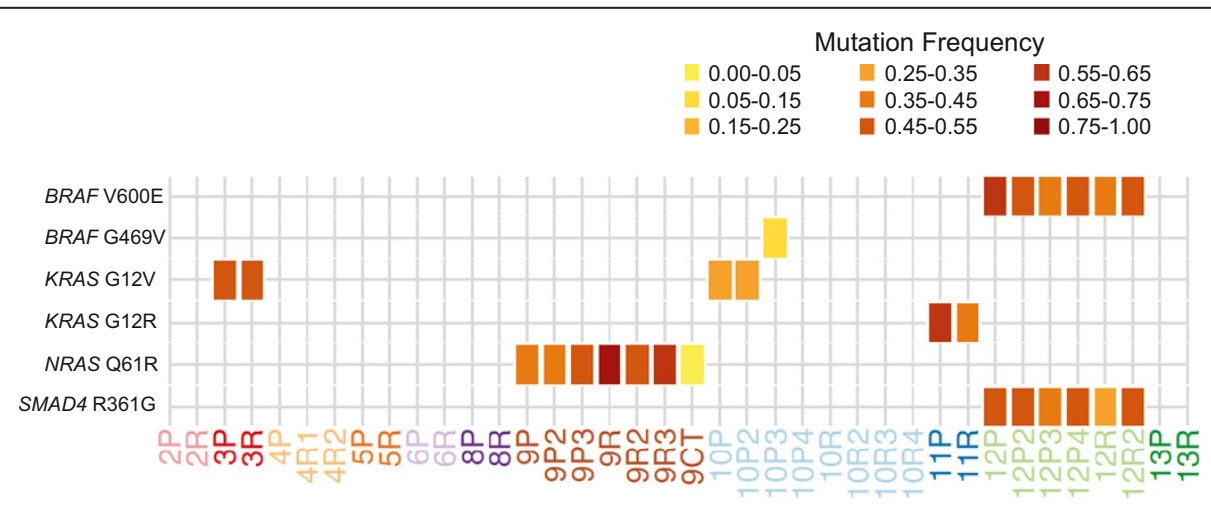

Figure 1 Average allele fraction of confirmed somatic mutations by ion torrent and MiSeq. The presence of a specific mutation (listed on left) in a specific tumor sample (listed at bottom) is indicated by a colored box in the corresponding position, with the shade of the box reflecting the average allele fraction as detected by lon Torrent and MiSeq. Corresponding normal samples are not shown, as these were all negative for the described mutations. 


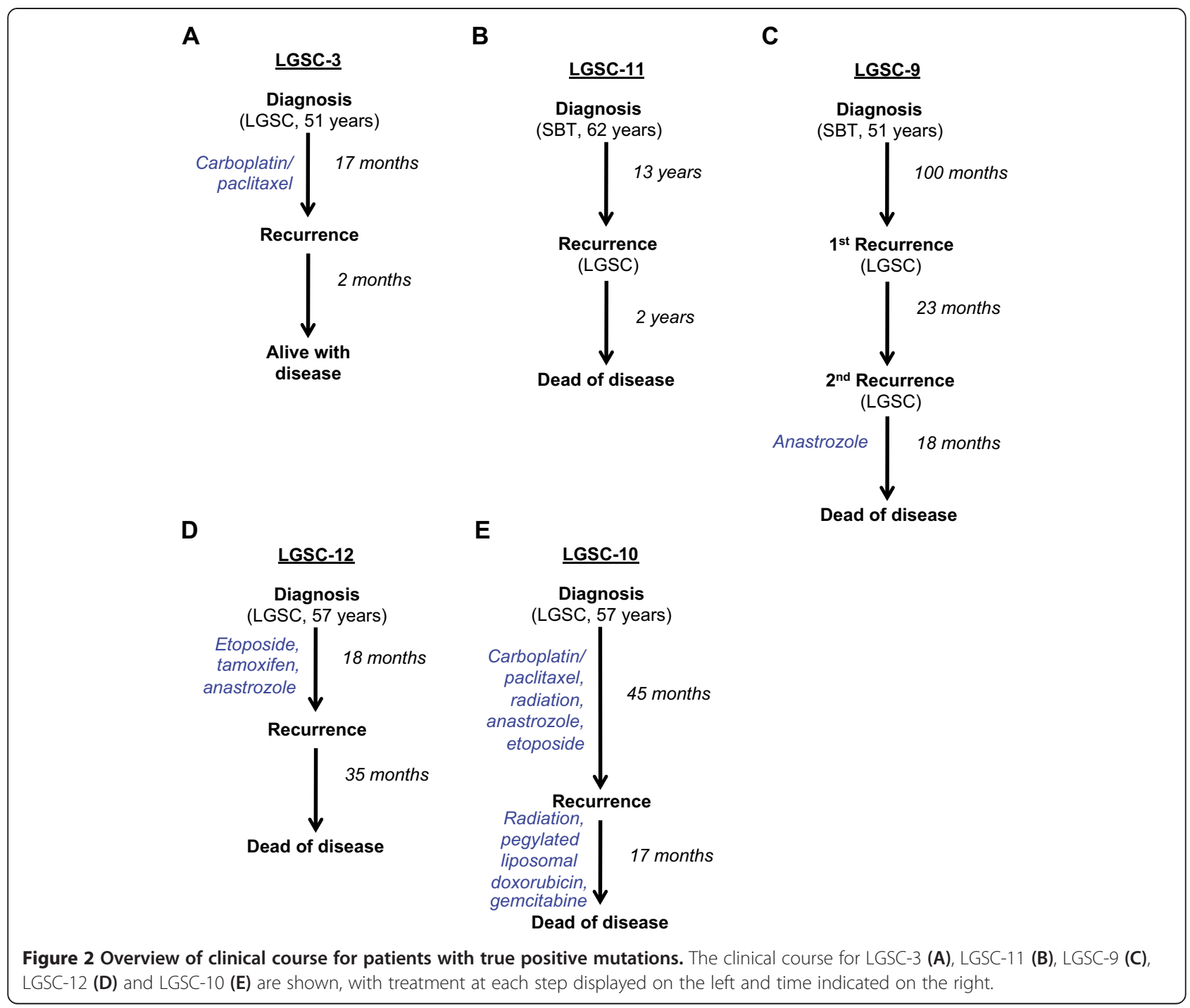

tumor samples assessed, including 3 samplings from the original SBT and 3 from the first recurrence of LGSC ( 2 from rectosigmoid and 1 from the left pelvic sidewall). The same mutation was also observed at a lower fraction $(5 \%)$ in a fresh ctDNA sample obtained following the second recurrence. The stability of this mutation among all 7 samples was confirmed by digital PCR (Figure 3/Additional file 20).

LGSC-12 is from a patient diagnosed with stage IIB LGSC at the age of 57 . Her disease was distributed throughout the pelvis with implants on the rectosigmoid colon. Following diagnosis, this patient was treated with etoposide (topoisomerase inhibitor), tamoxifen (estrogen receptor inhibitor) and anastrozole (non-steroidal aromatase inhibitor), before recurring 18 months later with LGSC involving the abdominal wall. She died of disease 53 months following her original LGSC diagnosis. Of note, this patient had a documented history of
SBT 36 years prior to her diagnosis with LGSC; however tissue samples were not available for analysis. Sequencing of 4 primary LGSC samples (including 2 from the pelvic tumor, 1 from the rectosigmoid tumor and 1 from a peri-aortic tumor nodule) and 2 recurrent LGSC samples (both from the abdominal wall tumor) revealed somatic non-synonymous mutations in both $B R A F$ (chr7:140,453,136A > T, V600E) and SMAD4 (chr18:48, $591,918 \mathrm{C}>\mathrm{G}, \mathrm{R} 361 \mathrm{G})$. Both of these mutations had an allelic fraction of $31-55 \%$ in all samples (BRAF median 51\%, range 37-55\%; SMAD4 median 49\%, range 31-51\%), suggesting that they were both stable over space and time (see Additional file 19 for confirmation by Sanger in select samples).

LGSC-10 is from a patient diagnosed with bilateral ovarian LGSC with extensive extra-ovarian involvement (stage IV) at the age of 57. Adjuvant treatment included 6 cycles of carboplatin/paclitaxel, radiation, anastrozole 


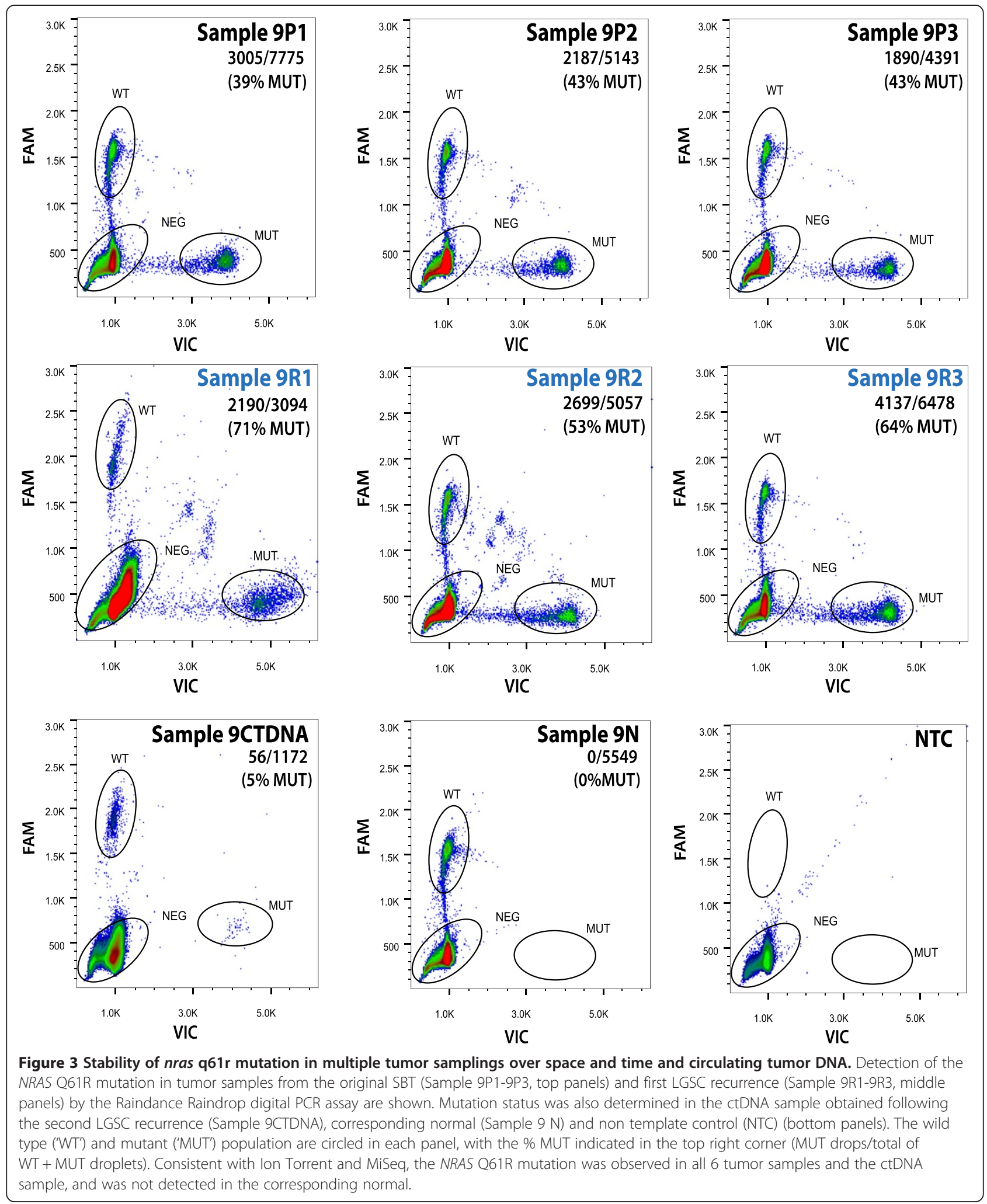

and etoposide. This patient recurred with LGSC 45 months later at which point she was treated with radiation, liposomal doxorubicin chemotherapy and gemcitabine before dying of her disease 62 months following initial diagnosis. Unlike cases LGSC-9 and LGSC-12, sequencing of 4 primary and 4 recurrent samples revealed extensive 
mutational variability. As shown by digital PCR in Figure 4 (and Additional file 20), 2 of 4 specimens from the primary setting, both from the right ovary, contained a KRAS G12V hotspot mutation (22-31\% allele fraction), while the specimen from the left ovary contained a low level (3-7\%) BRAF mutation (chr7:140,481,402C > A, G469V). Neither of these mutations were detected in the remaining specimen from the primary surgery (vaginal septal tumor) or any of the recurrent samples (including 3 from a right lower quadrant subcutaneous nodule and 1

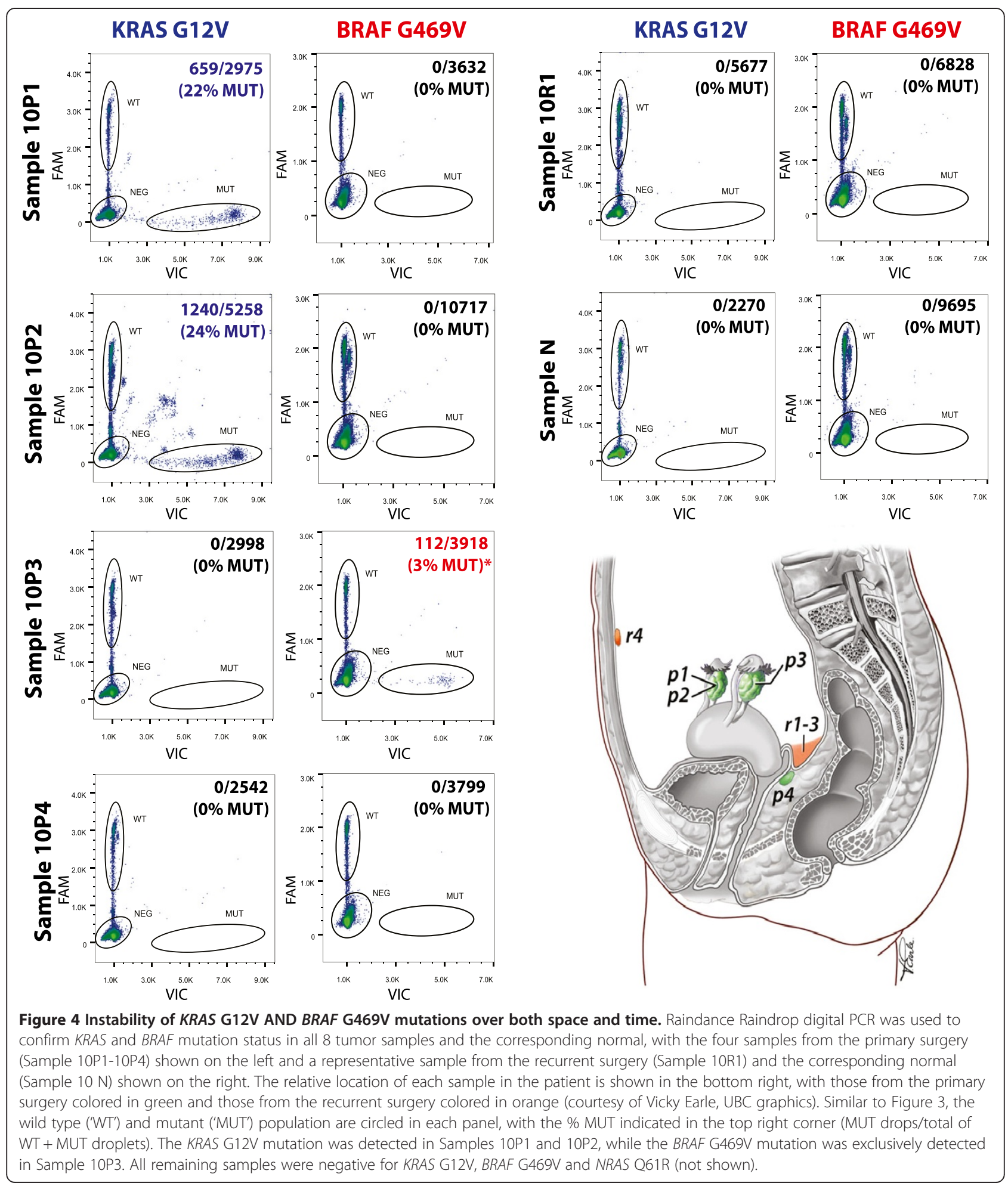


from an umbilical margin large nodule). This was not a reflection of tumor purity, as all mutation-negative specimens had comparable tumor cellularity by histopathologic assessment (80-95\%) and identical allele fractions of common SNPs in FGFR3 and PDGFRA ( $\geq 99 \%$, data not shown).

\section{Overall trends in mutational stability}

As shown in Table 2, four of five cases with true positive mutations were stable over time and/or space, including two cases that originally presented as SBT and recurred as an invasive LGSC. In contrast, one case showed instability of KRAS and BRAF over both space and time. Overall, mutations in NRAS and SMAD4 were stable in one case each, while genes mutated in more than one study case (KRAS and BRAF) showed different patterns of stability/instability for distinct variants (BRAF V600E vs. G469V, KRAS G12R vs. G12V) and even for the same variant (KRAS G12V).

\section{Discussion}

Among the 11 cases of LGSC sequenced in our study, only 7 confirmed somatic mutations were identified in 5 cases from a targeted hotspot panel of 46 cancerassociated genes. This low mutation rate is consistent with the detection of only 10 mutations per tumor by exome sequencing by Jones et al. [10], and further suggests that few mutational events are required to achieve malignancy. The frequency of mutations in LGSC is much lower than in other subtypes of ovarian carcinoma such as HGSC ( $\mathrm{n}=61$ mutations/tumor by exome sequencing) [29] and clear cell carcinoma $(n=34$ mutations/tumor by exome sequencing) [30]. This likely suggests that: [1] there is limited replication of precursor cells prior to initiation of tumorigenesis, [2] there are few bottlenecks once initiation occurs, and [3] the ratio of driver to passenger mutations should be higher than in other tumor types [10]. Consequently, targeted agents

Table 2 Overall trends in stability over time and space for confirmed somatic mutations in LGSC*

\begin{tabular}{|c|c|c|c|c|c|}
\hline & \multicolumn{2}{|c|}{ Time } & \multicolumn{3}{|c|}{ Time and Space } \\
\hline & LGSC-3 & LGSC-11 & LGSC-9 & LGSC-10 & LGSC-12 \\
\hline BRAF G469V & & & & Unstable & \\
\hline BRAF V600E & & & & & Stable \\
\hline KRAS G12R & & Stable & & & \\
\hline KRAS G12V & Stable & & & Unstable & \\
\hline NRAS Q61R & & & Stable & & \\
\hline SMAD47 R361G & & & & & Stable \\
\hline
\end{tabular}

*Only those mutations observed by two independent technologies (true positives) included.

Note: not all cases included in table as no confirmed somatic mutations in LGSC $-2,-4,-5$ or -13 ; mutations in LGSC -6 and -8 only observed by either Ion Torrent or MiSeq would likely be particularly effective in women with LGSC if key mutations are shown to be stable.

The most commonly reported drivers in LGSC are $K R A S$ and BRAF. We detected a KRAS mutation in three patients (including two stage IIIC and one stage IV) and a $B R A F$ mutation in two patients (including one stage IIB and one stage IV). Previous studies have reported conflicting findings with respect to mutation of $K R A S / B R A F$ and disease stage, with the Jones study [10] detecting $K R A S$ or $B R A F$ mutations in $4 / 13$ (31\%) and $3 / 13(23 \%)$ of stage III LGSC patients respectively. Additional studies report BRAF mutations in only $3 \%$ [12] and 5\% [13] of advanced stage LGSC. Grisham and Wong both reported that women with mutations in $K R A S$ and/or $B R A F[12,13]$ experience a more favorable outcome than women without these mutations. This positive prognostic effect appears to be dominated by $B R A F$ V600E mutations, with a lower incidence of stage III-IV disease, enrichment for SBT rather than invasive LGSC and reduced requirement for systemic treatment among women with this mutation [12,13]. Possible explanations include reports that SBTs from women with $B R A F$ mutations over-express genes with cell growth inhibitory effects [12] or that activating $B R A F$ mutations induce cellular senescence and prevent progression to LGSC [12,31-33]. In our study we observed a trend for increased mean overall survival in study patients with a MAPK pathway mutation (KRAS, BRAF, NRAS) compared to patients with wildtype status (92 months vs. 60 months respectively; $\mathrm{p}=0.23$ ); however, this difference in outcome was largely influenced by the two cases originally presenting as a SBT (143 and 183 months) and disappeared when these cases were excluded from the analysis.

The mutational status of NRAS, member of the MAPK pathway, showed stability over multiple different tumor sites and over a span of 8 years between original diagnosis with SBT and recurrence with an invasive LGSC (case LGSC-9). The presence of this stable feature at a low level in plasma ctDNA, obtained following a second recurrence of LGSC, also clearly highlights the potential utility of this source for disease monitoring (i.e. tumor response, persistence or recurrence).

SMAD4 mutational status in case LGSC-12 was also consistent among 6 tumor samples from 4 different sites in the primary and recurrence, and despite multiple treatment cycles. Although found to be unstable in another case, all samples from LGSC-12 also contained a $B R A F$ mutation at a similar allelic fraction. The observed SMAD4 mutation (chr18:48,591,918C > G, R361G) is at a highly conserved genomic position among placental mammals, and is situated within the C-terminus $\mathrm{MH} 2$ domain of the SMAD4 protein. This domain mediates protein-protein interactions and provides functional specificity and selectivity. It was previously reported 
as the most frequent target of SMAD4 missense mutations in human tumors, with a mutational hotspot corresponding to codons 330-370 [34]. Lassus et al. reported allelic loss at one or more loci at 18q12.3-q23 in 59\% of ovarian serous carcinomas (or $7.1 \%$ of grade 1 tumors), with lost or weak expression of SMAD4 protein in a subset of these tumors [35]. Mutations in SMAD4 have been reported to frequently co-exist with $K R A S$ mutations in colorectal cancer [36], and studies in pancreatic cancer suggest that wildtype SMAD4 blocks progression of KRAS G12D-initiated tumors [37]. In addition, mutation of KRAS, NRAS and BRAF [38-46], and loss of functional SMAD4 [47], have all been reported to predict resistance to anti-EGFR therapy. Unfortunately we were unable to assess the impact of the SMAD4 R361G mutation on protein expression by IHC in our samples, therefore we cannot comment on the utility of SMAD4 mutation status as a predictive marker in women with LGSC without further study.

In contrast to NRAS and SMAD4, mutations in KRAS and $B R A F$ were not stable in one patient (LGSC-10) in our study, despite traditionally being thought of as 'drivers' of tumorigenesis. This is akin to our recent observation that mutations in other key 'drivers' PIK3CA and CTNNB1 are only present in a subset of ovarian HGSC samples from the same patient [48]. These examples clearly defy the concept of oncogene addiction, which posits that the growth and survival of a tumor is dependent on a single dominant oncogene [49,50]. Our findings in LGSC-10 suggest that even at the time of primary diagnosis three distinct tumors/clones were present (i.e. $K R A S$-mutation positive, $B R A F$-mutation positive and $K R A S / B R A F$-mutation negative). As neither KRAS nor $B R A F$ were mutated in any of the recurrent samples, a different, as yet unidentified, dominant gene or pathway in the $K R A S / B R A F$-negative population was likely driving disease recurrence. One possibility is that we have missed a mutation in gene/s either directly or indirectly involved in the MAPK pathway that is not included on the targeted panel used to screen our samples. The KRAS and BRAF mutations were detected at an allelic fraction of $22-31 \%$ in the right ovary and $3-7 \%$ in the left ovary respectively, hence the clonal population containing an undetected driver mutation could have already been present in some or all of the tumor samples at primary debulking; expansion/recurrence of this population could then explain the absence of mutant KRAS/BRAF in the recurrent setting. In addition, mutations such as those in KRAS and $B R A F$ that occur early in the development of SBT/ LGSC [17] may not be required and/or advantageous for tumor maintenance once additional alterations are acquired. This phenomenon has previously been described in HGSC, in which secondary mutations in $B R C A 1 / 2$ restore protein function and result in acquired resistance to treatment [51]; however, reversion of both a KRAS and $B R A F$ mutation in the current scenario seems highly unlikely.

Of potential interest, LGSC-10 was the only study case diagnosed with stage IV disease and the only patient treated with radiation after primary diagnosis. While the presence of mutational instability in the primary setting (prior to treatment) argues against a direct impact of radiation, the possibility of instability exclusively in stage IV LGSC is an intriguing one that requires more study. To date, limited studies have reported on either temporal or spatial instability of $B R A F / K R A S$ mutations in SBT and LGSC. Instability in KRAS mutation status was recently described in a subset of matched SBT-LGSC pairs (2/5 cases discordant) [52] and matched SBT-peritoneal implant pairs (3/37 discordant for KRAS, while 14/14 concordant for $B R A F$ ) [53]. A recent study by Heublein et al. [54] also noted instability in $K R A S$ and $B R A F$ in 2/5 cases of bilateral SBT. In one case, a KRAS G12V mutation was detected in one ovary and a BRAF V600E mutation was detected in the contralateral ovary, while the other case contained a KRAS G12V and BRAF V600E mutation in one ovary and only a KRAS G12V mutation in the other ovary. This is consistent with our finding of spatial heterogeneity in the primary setting in LGSC-10. Unfortunately, a detailed breakdown of disease stage in cases with discordant vs. concordant sample pairs was not provided in any of these studies. Instability in KRAS has also been described for metastatic colorectal cancer [55,56]. Bossard et al. [55] reported several patterns of heterogeneity in KRAS mutation status in $22 \%$ of 18 colorectal carcinomas studied. This included exclusive presence in the primary tumor or metastatic site, presence in some metastases but not others, varied status among different samplings from the same metastatic site, and presence in the recurrent but not primary setting. Similarly, Otsuka et al. [56] reported the presence of a $K R A S$ mutation in metastatic sites but not the primary colorectal tumor in 1 of 9 patients studied; $B R A F$ mutation status was concordant in all cases, in contrast to what we observed.

Our finding that mutations in genes such as $K R A S$ or $B R A F$ are not necessarily stable features could provide an alternative explanation, in some patients, for the lack of correlation between response to selumetinib and KRAS/BRAF mutation status observed by Farley et al. [18]. Targeted sequencing (i.e. codon 599 of $B R A F$ and codons 12 and 13 of $K R A S$ ) using a single representative tumor sample from 34/52 (65\%) patients revealed a $B R A F$ and KRAS mutation in $2(6 \%)$ and 14 (41\%) cases respectively. A similar proportion of mutation positive vs. negative cases responded to selumetinib treatment, leading the authors to postulate that its activity may not depend on $B R A F / K R A S$ mutational activation. Tissue 
used for mutational analysis was obtained from the primary tumor in $82 \%$ of sequenced cases, metastatic tumor in $6 \%$ and recurrent or persistent tumor in $12 \%$ of cases. It is therefore possible that targetable mutations detected in the primary tumor were not present in the metastatic or recurrent tumor, or vice versa, leading to altered treatment response. It is also possible that some of these patients had undetected mutations in NRAS, a stable feature in our study, which also predicts response to MEK inhibitors.

It is important to recognize the limitations of our study, most notably small sample size and use of a hotspot targeted gene panel. Firstly, the small number of cases used in this study (despite being a collaboration between three institutions) is illustrative of the challenge in identifying primary-recurrent pairs for a rare tumor type such as LGSC. Confirmation of our findings in a larger cohort of LGSC will therefore require participation by multiple institutions or establishment of a worldwide registry. Secondly, by limiting the sequencing discovery phase to a panel of hotspot mutations in 46 genes, it is highly likely that we have missed additional case-specific mutations in our study population. However, a closer look at the mutations discovered by Jones et al. through exome sequencing [10] revealed that only $K R A S$ and BRAF were recurrently mutated in LGSC. This suggests that it is also unlikely that we have missed additional recurrent drivers of disease, although patientspecific drivers outside the normal patterns of LGSC may exist. Thirdly, we have not investigated potential alternative drivers of disease that may be important in cases without identified somatic mutations, such as copy number alterations, epigenetic changes or microRNAs. Singer et al. [57] previously reported a progressive increase in copy number alterations from SBT through to LGSC, most notably allelic imbalance of chromosomes $1 \mathrm{p}, 5 \mathrm{q}, 8 \mathrm{p}, 18 \mathrm{q}$ and $22 \mathrm{q}$. This was confirmed by Kuo et al. [58] who reported an increased chromosomal instability index in LGSC relative to SBT, suggesting that amplifications, deletions and aneuploidy play a role in the malignant transformation of SBT. Hemizygous deletion of chromosome 1p36 was especially enriched in LGSC samples; this region contains the microRNA miR$34 \mathrm{a}$, which was found to have an anti-proliferative and pro-apoptotic effect in an LGSC cell line [58]. Finally, several groups have reported on differential methylation patterns in SBT and LGSC [59-61], suggesting that methylation-induced transcriptional silencing of tumor suppressor genes may play an undefined role in malignant transformation and progression and response to systemic or targeted therapy.

\section{Conclusions}

The extent of intratumoral heterogeneity in kidney, breast, leukemia and ovarian cancers has recently been described [48,62-64]. Most papers have focused on highgrade cancers with many somatic mutations, and most of the mutations described have no immediate clinical relevance. Herein we show that, in a cancer type known to have a sparse mutational landscape [10], heterogeneity in targetable mutations can be observed. While the vast majority of evaluable cases contained mutations that were detected in all samples, one case showed remarkable instability in hotspot mutations of presumed drivers of disease, despite not receiving treatment that could have driven the specific evolution of (KRAS/BRAF) mutant clones. In addition, as we looked within a limited mutational space, the possibility remains that more underlying heterogeneity may be revealed in more cases with further study. Investigation of additional cases is required to confirm whether a consistent minority of LGSC cases show clinically relevant mutational heterogeneity; this would necessitate a change in clinical trial design with contemporary samplings of a cancer required to guide treatment decisions. Alternatively, if not found to be a general phenomenon upon further study, confirmation of mutational status in a single sample would be sufficient.

\section{Additional files}

\section{Additional file 1: "Additional Information on Study Samples". Provides more detailed information on pathologic diagnosis, DNA quantity and estimated cellularity.}

Additional file 2: "LGSC-2 Case Images". LGSC-2 is from a patient diagnosed with bilateral ovarian LGSC (stage IIIC) at 57 years old (LGSC-2-P, top) and metastatic LGSC 46 months after primary diagnosis (LGSC-2-R, bottom; both 20X).

Additional file 3: "LGSC-3 Case Images". LGSC-3 is from a patient diagnosed with bilateral ovarian LGSC (stage IIIC) at 51 years old (LGSC-3-P, top), and recurrent LGSC 17 months later (LGSC-3-R, bottom; both 20X)

Additional file 4: "LGSC-4 Case Images". LGSC-4 is from a patient diagnosed with ovarian LGSC (IIIB) at the age of 66 (LGSC-4-P), followed by two separate recurrences 25 months (LGSC-4-R1) and 45 months (LGSC-4-R2) later (all 20X).

Additional file 5: "LGSC-5 Case Images". LGSC-5 is from a patient diagnosed with LGSC (stage IIIC) at age 51 (LGSC-5-P, top) and recurrent LGSC 37 months later (LGSC-5-R, bottom; both images 100X).

Additional file 6: "LGSC-6 Case Images". LGSC-6 is from a patient diagnosed with LGSC (stage IIIC) at 41 years old (LGSC-6-P, top) and recurrent LGSC 24 months later (LGSC-6-R, bottom; both images 100X).

Additional file 7: "LGSC-8 Case Images". LGSC-8 is from a patient diagnosed with metastatic LGSC (stage IIIC) at the age of 33 (LGSC-8-P, top), with disease recurrence 7 months later (LGSC-8-R, bottom; both images 100X).

Additional file 8: "LGSC-9 Case Images". LGSC-9 is from a patient diagnosed with a serous borderline tumor (stage IIIB) at age 51 (LGSC-9-P1, LGSC-9-P2, LGSC-9-R3 shown in left panels). This patient received no additional treatment after surgical resection and recurred with LGSC 100 months later (LGSC-9-R1, LGSC-9-R2, LGSC-9-R3 shown in right panels; all images 20X).

Additional file 9: "LGSC-10 Case Images". LGSC-10 is from a patient diagnosed with bilateral ovarian LGSC (stage IV) at the age of 57 
(LGSC-10-P1, LGSC-10-P2, LGSC-10-P3, LGSC-10-P4 shown in left panels), followed by disease recurrence 45 months later (LGSC-10-R1, LGSC-10-R2, LGSC-10-R3, LGSC-10-R4 shown in right panels; all images at 20X).

Additional file 10: "LGSC-11 Case Images". LGSC-11 is from a patient diagnosed with a serous borderline tumor (stage IIIC) at 62 years (LGSC-11-P, top) followed by recurrence with LGSC 13 years later (LGSC-11-R, bottom; both images at 20X).

Additional file 11: "LGSC-12 Case Images". LGSC-12 is from a patient diagnosed with LGSC (stage IIB) at the age of 57 (LGSC-12-P1, LGSC-12-P2, LGSC-12-P3, LGSC-12-P4 are shown). This patient was treated with etoposide, tamoxifen and anastrozole prior to recurrence with LGSC 18 months later (LGSC-12-R1, LGSC-12-R2 are shown; all images at 20X).

Additional file 12: "LGSC-13 Case Images". LGSC-13 is from a patient diagnosed with LGSC (stage IIIB) at the age of 58 (LGSC-13-P, top), followed by recurrence with LGSC 46 months later (LGSC-13-R, bottom; both images 20X).

Additional file 13: "Supplemental Methods". Describes additional methodological details for DNA extraction, sequencing and digital PCR.

Additional file 14: "Genes/Mutations on lon Torrent AmpliSeq panel v1". Lists genes and hot spot mutations included on the lon Torrent Ampliseq panel.

Additional file 15: "Primer sequences for Sanger sequencing". Lists primer sequences used for validation of mutations by Sanger sequencing.

Additional file 16: "Primer sequences for digital PCR". Lists primer sequences used for validation of mutations by digital PCR.

Additional file 17: "Allele fraction of confirmed somatic mutations by lon Torrent and MiSeq". The presence of a specific mutation (listed on left) in a specific tumor sample (listed at bottom) is indicated by a colored box in the corresponding position, with the shade of the box reflecting the allelic fraction as detected by (A) Ion Torrent or (B) MiSeq. Corresponding normal samples were all negative for the described mutations.

Additional file 18: "Ion Torrent and MiSeq reads for true positive mutations". Lists the variant reads, total reads and variant frequency by sample for both lon Torrent and MiSeq.

Additional file 19: "Stable KRAS, BRAF and SMAD4 mutations in cases 3 and 12 by Sanger sequencing". Detection of the KRAS G12V mutation by Sanger sequencing in LGSC-3-P (A) and LGSC-3-R (B) are shown. Sanger sequencing also confirmed the presence of the BRAF V600E and the SMAD4 R361G mutation in LGSC-12-P1 (C and $\mathbf{F}$ respectively) and LGSC-12-R1 (D and $\mathbf{G}$ respectively), but not the corresponding normal sample LGSC-12-N (E and $\mathrm{H}$ respectively).

Additional file 20: "Digital PCR results". Lists the \% mutant and \% wildtype droplets corresponding to the digital PCR results shown in Figures 3 and 4.

\section{Abbreviations}

BCCA: BC cancer agency; BRAF: V-raf murine sarcoma viral oncogene homolog B1; ctDNA: Circulating tumor DNA; DNA: Deoxyribonucleic acid; ERK: Extracellular signal-regulated kinase; FFPE: Formalin-fixed paraffinembedded; FGFR3: Fibroblast growth factor receptor 3; HGSC: High-grade serous carcinoma; KRAS: Kirsten rat sarcoma viral oncogene homolog; LGSC: Low-grade serous carcinoma; MAPK: Mitogen-activated kinase; MDACC: MD Anderson cancer centre; MEK: MAP kinase kinase; NRAS: Neuroblastoma RAS viral (v-ras) oncogene homolog; PCR: Polymerase chain reaction; PDGFRA: Platelet-derived growth factor receptor alpha; SBT: Serous borderline tumor; SMAD4: Mothers against decapentaplegic homolog 4; SNV: Single nucleotide variant; UHN: University health network.

\section{Competing interests}

The authors declare that they have no competing interests.

\section{Authors' contributions}

AAT contributed to study design, data collection, analysis and interpretation, generation of figures, literature searches and writing of the manuscript. MM contributed to data collection, data analysis, data interpretation, generation of figures and writing of the manuscript. WY contributed to data collection and data analysis. JD performed data analysis and contributed to generation of figures and writing of the manuscript. SY and EK contributed to data collection. KKW, DG, HM, BG, AVT, JM and BC all participated in the conceptualization of the study/study design and sample selection/ acquisition. SS contributed to data analysis. DH participated in the conceptualization and design of the study, data interpretation, manuscript preparation and supervised the project. All authors read and approved the final manuscript.

\section{Authors' information}

Alicia A. Tone, PhD

Scientific Associate II

Melissa K. McConechy, BSc

Doctoral Candidate

David Huntsman, MD, FRCPC, FCCMG

Dr. Chew Wei Memorial Professor of Gynaecologic Oncology

UBC Professor, Departments of Pathology \& Lab Medicine and Obstetrics \& Gynaecology UBC Director of OvCaRe, Vancouver General Hospital, BC Cancer Agency

UBC Medical Director, Centre for Translational and Applied Genomics, PHSA Laboratories

\section{Acknowledgements}

We would like to acknowledge our funding sources, including the BC Cancer Foundation, VGH + UBC Hospital Foundation, Canadian Cancer Society Research Institute Impact Grant led by D. Huntsman (Contextual genomics: The foundation for subtype specific approaches to ovarian cancer control) and The University of Texas MD Anderson Cancer Centre Specialized Program of Research Excellence in Ovarian Cancer NIH grant \# P50 CA08369.

\section{Author details}

'Department of Pathology and Laboratory Medicine, University of British Columbia, Vancouver, BC, Canada. ${ }^{2}$ BC Cancer Agency, Room 3427, 600 West 10th Avenue, Vancouver, BC, Canada. ${ }^{3}$ Division of Gynecologic Oncology, Princess Margaret Cancer Centre, Toronto, ON, Canada. ${ }^{4}$ Department of Computer Science, University of British Columbia, Vancouver, BC, Canada. ${ }^{5}$ Department of Gynecologic Oncology \& Reproductive Medicine, University of Texas MD Anderson Cancer Center, Houston, TX, USA. ${ }^{6}$ Division of Medical Oncology and Hematology, Princess Margaret Hospital, Toronto, ON, Canada. ${ }^{7}$ Laboratory Medicine and Pathobiology, University of Toronto, Toronto, ON, Canada. ${ }^{8}$ Obstetrics and Gynecology, University of British Columbia, Vancouver, BC, Canada.

Received: 22 July 2014 Accepted: 11 December 2014 Published: 18 December 2014

\section{References}

1. Gershenson DM, Sun CC, Lu KH, Coleman RL, Sood AK, Malpica A, Deavers MT, Silva EG, Bodurka DC: Clinical behavior of stage II-IV low-grade serous carcinoma of the ovary. Obstet Gynecol 2006, 108(2):361-368.

2. Schmeler KM, Gershenson DM: Low-grade serous ovarian cancer: a unique disease. Curr Oncol Rep 2008, 10(6):519-523.

3. Diaz-Padilla I, Malpica AL, Minig L, Chiva LM, Gershenson DM, GonzalezMartin A: Ovarian low-grade serous carcinoma: a comprehensive update. Gynecol Oncol 2012, 126(2):279-285.

4. Bodurka DC, Deavers MT, Tian C, Sun CC, Malpica A, Coleman RL, Lu KH, Sood AK, Birrer MJ, Ozols R, Baergen R, Emerson RE, Steinhoff M, Behmaram B, Rasty G, Gershenson DM: Reclassification of serous ovarian carcinoma by a 2-tier system: a gynecologic oncology group study. Cancer 2012, 118(12):3087-3094.

5. Malpica A, Deavers MT, Lu K, Bodurka DC, Atkinson EN, Gershenson DM, Silva EG: Grading ovarian serous carcinoma using a two-tier system. Am J Surg Pathol 2004, 28(4):496-504.

6. Vang R, Shih le M, Kurman RJ: Ovarian low-grade and high-grade serous carcinoma: pathogenesis, clinicopathologic and molecular biologic features, and diagnostic problems. Adv Anat Pathol 2009, 16(5):267-282.

7. Schmeler KM, Sun CC, Bodurka DC, Deavers MT, Malpica A, Coleman RL, Ramirez PT, Gershenson DM: Neoadjuvant chemotherapy for low-grade serous carcinoma of the ovary or peritoneum. Gynecol Oncol 2008, 108(3):510-514. 
8. Gershenson DM, Sun CC, Bodurka D, Coleman RL, Lu KH, Sood AK, Deavers M Malpica AL, Kavanagh JJ: Recurrent low-grade serous ovarian carcinoma is relatively chemoresistant. Gynecol Oncol 2009, 114(1):48-52.

9. Fader AN, Java J, Ueda S, Bristow RE, Armstrong DK, Bookman MA Gershenson DM: Survival in women with grade 1 serous ovarian carcinoma. Obstet Gynecol 2013, 122(2 Pt 1):225-232.

10. Jones S, Wang TL, Kurman RJ, Nakayama K, Velculescu VE, Vogelstein B, Kinzler KW, Papadopoulos N, Shih le M: Low-grade serous carcinomas of the ovary contain very few point mutations. J Pathol 2012, 226(3):413-420.

11. Singer G, Oldt R III, Cohen Y, Wang BG, Sidransky D, Kurman RJ, Shih le M: Mutations in BRAF and KRAS characterize the development of low-grade ovarian serous carcinoma. J Natl Cancer Inst 2003, 95(6):484-486.

12. Wong KK, Tsang YT, Deavers MT, Mok SC, Zu Z, Sun C, Malpica A, Wolf JK, $\mathrm{Lu} \mathrm{KH}$, Gershenson DM: BRAF mutation is rare in advanced-stage lowgrade ovarian serous carcinomas. Am J Pathol 2010, 177(4):1611-1617.

13. Grisham RN, lyer G, Garg K, DeLair D, Hyman DM, Zhou Q, lasonos A, Berger MF, Dao F, Spriggs DR, Levine DA, Aghajanian C, Solit DB: BRAF mutation is associated with early stage disease and improved outcome in patients with low-grade serous ovarian cancer. Cancer 2013, 119(3):548-554.

14. Romero I, Sun CC, Wong KK, Bast RC Jr, Gershenson DM: Low-grade serous carcinoma: new concepts and emerging therapies. Gynecol Oncol 2013, 130(3):660-666.

15. Staebler A, Heselmeyer-Haddad K, Bell K, Riopel M, Perlman E, Ried T, Kurman RJ: Micropapillary serous carcinoma of the ovary has distinct patterns of chromosomal imbalances by comparative genomic hybridization compared with atypical proliferative serous tumors and serous carcinomas. Hum Pathol 2002, 33(1):47-59.

16. Crispens MA, Bodurka D, Deavers M, Lu K, Silva EG, Gershenson DM: Response and survival in patients with progressive or recurrent serous ovarian tumors of low malignant potential. Obstet Gynecol 2002, 99(1):3-10.

17. Ho CL, Kurman RJ, Dehari R, Wang TL, Shih IM: Mutations of BRAF and KRAS precede the development of ovarian serous borderline tumors. Cancer Res 2004, 64(19):6915-6918.

18. Farley J, Brady WE, Vathipadiekal V, Lankes HA, Coleman R, Morgan MA, Mannel R, Yamada SD, Mutch D, Rodgers WH, Birrer M, Gershenson DM: Selumetinib in women with recurrent low-grade serous carcinoma of the ovary or peritoneum: an open-label, single-arm, phase 2 study. Lancet Oncol 2013, 14(2):134-140.

19. Nakayama N, Nakayama K, Yeasmin S, Ishibashi M, Katagiri A, lida K, Fukumoto M, Miyazaki K: KRAS or BRAF mutation status is a usefu predictor of sensitivity to MEK inhibition in ovarian cancer. $\mathrm{Br} J$ Cancer 2008, 99(12):2020-2028.

20. Allen LF, Sebolt-Leopold J, Meyer MB: Cl-1040 (PD184352), a targeted signal transduction inhibitor of MEK (MAPKK). Semin Oncol 2003, 30(5 Suppl 16):105-116.

21. Pohl G, Ho CL, Kurman RJ, Bristow R, Wang TL, Shih IM: Inactivation of the mitogen-activated protein kinase pathway as a potential target-based therapy in ovarian serous tumors with KRAS or BRAF mutations. Cancer Res 2005, 65(5):1994-2000.

22. Rothberg JM, Hinz W, Rearick TM, Schultz J, Mileski W, Davey M, Leamon JH, Johnson K, Milgrew MJ, Edwards M, Hoon J, Simons JF, Marran D, Myers JW, Davidson JF, Branting A, Nobile JR, Puc BP, Light D, Clark TA, Huber M, Branciforte JT, Stoner IB, Cawley SE, Lyons M, Fu Y, Homer N, Sedova M, Miao X, Reed B et al: An integrated semiconductor device enabling non-optical genome sequencing. Nature 2011, 475(7356):348-352.

23. Li H, Durbin R: Fast and accurate long-read alignment with BurrowsWheeler transform. Bioinformatics 2010, 26(5):589-595.

24. Ding J, Bashashati A, Roth A, Oloumi A, Tse K, Zeng T, Haffari G, Hirst M, Marra MA, Condon A, Aparicio S, Shah SP: Feature-based classifiers for somatic mutation detection in tumour-normal paired sequencing data. Bioinformatics 2012, 28(2):167-175

25. Reva B, Antipin Y, Sander C: Predicting the functional impact of protein mutations: application to cancer genomics. Nucleic Acids Res 2011 39(17):e118

26. Li H: Aligning Sequence Reads, Clone Sequences and Assembly Contigs with bwa-mem. arXiv Preprint arXiv. 2013:1303.

27. McConechy MK, Anglesio MS, Kalloger SE, Yang W, Senz J, Chow C, HeraviMoussavi A, Morin GB, Mes-Masson AM, Carey MS, McAlpine JN, Kwon JS, Prentice LM, Boyd N, Shah SP, Gilks CB, Huntsman DG: Subtype-specific mutation of PPP2R1A in endometrial and ovarian carcinomas. J Pathol 2011, 223(5):567-573.

28. Geisler J: Differences between the non-steroidal aromatase inhibitors anastrozole and letrozole-of clinical importance? Br J Cancer 2011, 104(7):1059-1066.

29. Cancer Genome Atlas Research Network: Integrated genomic analyses of ovarian carcinoma. Nature 2011, 474(7353):609-615.

30. Jones S, Wang TL, Shih le M, Mao TL, Nakayama K, Roden R, Glas R, Slamon D, Diaz LA Jr, Vogelstein B, Kinzler KW, Velculescu VE, Papadopoulos N: Frequent mutations of chromatin remodeling gene ARID1A in ovarian clear cell carcinoma. Science 2010, 330(6001):228-231.

31. Dhomen N, Reis-Filho JS, da Rocha Dias S, Hayward R, Savage K, Delmas V, Larue L, Pritchard C, Marais R: Oncogenic Braf induces melanocyte senescence and melanoma in mice. Cancer Cell 2009, 15(4):294-303.

32. Wajapeyee N, Serra RW, Zhu X, Mahalingam M, Green MR: Oncogenic BRAF induces senescence and apoptosis through pathways mediated by the secreted protein IGFBP7. Cell 2008, 132(3):363-374.

33. Zeppernick F, Ardighieri L, Hannibal CG, Vang R, Junge J, Kjaer SK, Zhang $R_{\text {, }}$ Kurman RJ, Shih IM: BRAF mutation is associated with a specific cell type with features suggestive of senescence in ovarian serous borderline (Atypical Proliferative) tumors. Am J Surg Pathol. 2014, 38(12):1603-1611.

34. lacobuzio-Donahue CA, Song J, Parmiagiani G, Yeo CJ, Hruban RH, Kern SE: Missense mutations of MADH4: characterization of the mutational hot spot and functional consequences in human tumors. Clin Cancer Res 2004, 10(5):1597-1604.

35. Lassus H, Salovaara R, Aaltonen LA, Butzow R: Allelic analysis of serous ovarian carcinoma reveals two putative tumor suppressor loci at 18q22-q23 distal to SMAD4, SMAD2, and DCC. Am J Pathol 2001, 159(1):35-42.

36. Sameer AS, Chowdri NA, Syeed N, Banday MZ, Shah ZA, Siddiqi MA: SMAD4-molecular gladiator of the TGF-beta signaling is trampled upon by mutational insufficiency in colorectal carcinoma of Kashmiri population: an analysis with relation to KRAS proto-oncogene. BMC Cancer. 2010, 10:300.

37. Bardeesy N, Cheng KH, Berger JH, Chu GC, Pahler J, Olson P, Hezel AF, Horner J, Lauwers GY, Hanahan D, DePinho RA: Smad4 is dispensable for normal pancreas development yet critical in progression and tumor biology of pancreas cancer. Genes Dev 2006, 20(22):3130-3146.

38. Vakiani E, Solit DB: KRAS and BRAF: drug targets and predictive biomarkers. J Pathol 2011, 223(2):219-229.

39. Miller VA, Riely GJ, Zakowski MF, Li AR, Patel JD, Heelan RT, Kris MG, Sandler AB, Carbone DP, Tsao A, Herbst RS, Heller G, Ladanyi M, Pao W, Johnson DH: Molecular characteristics of bronchioloalveolar carcinoma and adenocarcinoma, bronchioloalveolar carcinoma subtype, predict response to erlotinib. J Clin Oncol 2008, 26(9):1472-1478.

40. Pao W, Wang TY, Riely GJ, Miller VA, Pan Q, Ladanyi M, Zakowski MF, Heelan RT, Kris MG, Varmus HE: KRAS mutations and primary resistance of lung adenocarcinomas to gefitinib or erlotinib. PLoS Med 2005, 2(1):e17.

41. Zhu CQ, da Cunha Santos G, Ding K, Sakurada A, Cutz JC, Liu N, Zhang T, Marrano P, Whitehead M, Squire JA, Kamel-Reid S, Seymour L, Shepherd FA, Tsao MS: Role of KRAS and EGFR as biomarkers of response to Erlotinib in national cancer institute of Canada clinical trials group study BR.21 J Clin Oncol 2008, 26(26):4268-4275.

42. Hirsch FR, Varella-Garcia M, Cappuzzo F, McCoy J, Bemis L, Xavier AC, Dziadziuszko R, Gumerlock P, Chansky K, West H, Gazdar AF, Crino L, Gandara DR, Franklin WA, Bunn PA Jr: Combination of EGFR gene copy number and protein expression predicts outcome for advanced non-small-cell lung cancer patients treated with gefitinib. Ann Oncol 2007, 18(4):752-760

43. Eberhard DA, Johnson BE, Amler LC, Goddard AD, Heldens SL, Herbst RS, Ince $\mathrm{WL}$, Janne PA, Januario T, Johnson DH, Klein P, Miller VA, Ostland MA, Ramies DA, Sebisanovic D, Stinson JA, Zhang YR, Seshagiri S, Hillan KJ: Mutations in the epidermal growth factor receptor and in KRAS are predictive and prognostic indicators in patients with non-small-cell lung cancer treated with chemotherapy alone and in combination with erlotinib. J Clin Oncol 2005, 23(25):5900-5909.

44. Janakiraman M, Vakiani E, Zeng Z, Pratilas CA, Taylor BS, Chitale D, Halilovic E, Wilson M, Huberman K, Ricarte Filho JC, Persaud $Y$, Levine DA, Fagin JA, Jhanwar SC, Mariadason JM, Lash A, Ladanyi M, Saltz LB, Heguy A, Paty PB, Solit DB: Genomic and biological characterization of exon 4 KRAS mutations in human cancer. Cancer Res 2010, 70(14):5901-5911. 
45. De Roock W, Claes B, Bernasconi D, De Schutter J, Biesmans B, Fountzilas G, Kalogeras KT, Kotoula V, Papamichael D, Laurent-Puig P, Penault-Llorca F, Rougier P, Vincenzi B, Santini D, Tonini G, Cappuzzo F, Frattini M, Molinari F, Saletti P, De Dosso S, Martini M, Bardelli A, Siena S, Sartore-Bianchi A Tabernero J, Macarulla T, Di Fiore F, Gangloff AO, Ciardiello F, Pfeiffer P et al: Effects of KRAS, BRAF, NRAS, and PIK3CA mutations on the efficacy of cetuximab plus chemotherapy in chemotherapy-refractory metastatic colorectal cancer: a retrospective consortium analysis. Lancet Oncol 2010, 11(8):753-762.

46. Loupakis F, Ruzzo A, Cremolini C, Vincenzi B, Salvatore L, Santini D, Masi G, Stasi I, Canestrari E, Rulli E, Floriani I, Bencardino K, Galluccio N, Catalano V, Tonini G, Magnani M, Fontanini G, Basolo F, Falcone A, Graziano F: KRAS codon 61,146 and BRAF mutations predict resistance to cetuximab plus irinotecan in KRAS codon 12 and 13 wild-type metastatic colorectal cancer. Br J Cancer 2009, 101(4):715-721.

47. Herman JM, Fan KY, Wild AT, Wood LD, Blackford AL, Donehower RC, Hidalgo M, Schulick RD, Edil BH, Choti MA, Hruban RH, Pawlik TM, Cameron JL, Laheru DA, lacobuzio-Donahue CA, Wolfgang CL: Correlation of Smad4 status with outcomes in patients receiving erlotinib combined with adjuvant chemoradiation and chemotherapy after resection for pancreatic adenocarcinoma. Int J Radiat Oncol Biol Phys 2013, 87(3):458-459.

48. Bashashati A, Ha G, Tone A, Ding J, Prentice LM, Roth A, Rosner J, Shumansky K, Kalloger S, Senz J, Yang W, McConechy M, Melnyk N, Anglesio M, Luk MT, Tse K, Zeng T, Moore R, Zhao Y, Marra MA, Gilks B, Yip S, Huntsman DG, McAlpine JN, Shah SP: Distinct evolutionary trajectories of primary high-grade serous ovarian cancers revealed through spatial mutational profiling. J Patho/ 2013, 231(1):21-34

49. Weinstein IB: Cancer. Addiction to oncogenes-the Achilles heal of cancer. Science 2002, 297(5578):63-64.

50. Torti $D$, Trusolino $L$ : Oncogene addiction as a foundational rationale for targeted anti-cancer therapy: promises and perils. EMBO Mol Med 2011, 3(11):623-636.

51. Dhillon KK, Swisher EM, Taniguchi T: Secondary mutations of BRCA1/2 and drug resistance. Cancer Sci 2011, 102(4):663-669.

52. Tsang YT, Deavers MT, Sun CC, Kwan SY, Kuo E, Malpica A, Mok SS, Gershenson DM, Wong KK: KRAS (but not BRAF) mutations in ovarian serous borderline tumor are associated with recurrent low-grade serous carcinoma. J Pathol. 2013, 231(4):449-456.

53. Ardighieri L, Zeppernick F, Hannibal CG, Vang R, Cope L, Junge J, Kjaer SK, Kurman RJ, Shih I-M: Mutational analysis of BRAF and KRAS in ovarian serous borderline (atypical proliferative) tumours and associated peritoneal implants. J Pathol 2014, 232:16-22.

54. Heublein S, Grasse K, Hessel H, Burges A, Lenhard M, Engel J, Kirchner T, Jeschke U, Mayr D: KRAS, BRAF genotyping reveals genetic heterogeneity of ovarian borderline tumors and associated implants. BMC Cancer. 2013, 13:483.

55. Bossard C, Kury S, Jamet P, Senellart H, Airaud F, Ramee JF, Bezieau S, Matysiak-Budnik T, Laboisse CL, Mosnier JF: Delineation of the infrequent mosaicism of KRAS mutational status in metastatic colorectal adenocarcinomas. J Clin Pathol 2012, 65(5):466-469.

56. Otsuka K, Satoyoshi R, Nanjo H, Miyazawa H, Abe Y, Tanaka M, Yamamoto Y, Shibata $\mathrm{H}$ : Acquired/intratumoral mutation of KRAS during metastatic progression of colorectal carcinogenesis. Oncol Lett 2012, 3(3):649-653.

57. Singer G, Kurman RJ, Chang HW, Cho SK, Shih IM: Diverse tumorigenic pathways in ovarian serous carcinoma. Am J Pathol 2002, 160(4):1223-1228.

58. Kuo KT, Guan B, Feng Y, Mao TL, Chen $X$, Jinawath N, Wang $Y$, Kurman RJ, Shih le M, Wang TL: Analysis of DNA copy number alterations in ovarian serous tumors identifies new molecular genetic changes in low-grade and high-grade carcinomas. Cancer Res 2009, 69(9):4036-4042.

59. Zeller C, Dai W, Curry E, Siddiq A, Walley A, Masrour N, Kitsou-Mylona I, Anderson G, Ghaem-Maghami S, Brown R, El-Bahrawy M: The DNA methylomes of serous borderline tumors reveal subgroups with malignant- or benign-like profiles. Am J Pathol 2013, 182(3):668-677.

60. Keita M, Wang ZQ, Pelletier JF, Bachvarova M, Plante M, Gregoire J, Renaud MC, Mes-Masson AM, Paquet ER, Bachvarov D: Global methylation profiling in serous ovarian cancer is indicative for distinct aberrant DNA methylation signatures associated with tumor aggressiveness and disease progression. Gynecol Oncol 2013, 128(2):356-363.

61. Shih le M, Chen L, Wang CC, Gu J, Davidson B, Cope L, Kurman RJ, Xuan J, Wang TL: Distinct DNA methylation profiles in ovarian serous neoplasms and their implications in ovarian carcinogenesis. Am J Obstet Gynecol 2010, 203(6):584. e1-22.
62. Gerlinger M, Rowan AJ, Horswell S, Larkin J, Endesfelder D, Gronroos E, Martinez P, Matthews N, Stewart A, Tarpey P, Varela I, Phillimore B, Begum S, McDonald NQ, Butler A, Jones D, Raine K, Latimer C, Santos CR, Nohadani M, Eklund AC, Spencer-Dene B, Clark G, Pickering L, Stamp G, Gore M, Szallasi Z, Downward J, Futreal PA, Swanton C: Intratumor heterogeneity and branched evolution revealed by multiregion sequencing. N Engl J Med 2012, 366(10):883-892.

63. Shah SP, Morin RD, Khattra J, Prentice L, Pugh T, Burleigh A, Delaney A, Gelmon K, Guliany R, Senz J, Steidl C, Holt RA, Jones S, Sun M, Leung G, Moore R, Severson T, Taylor GA, Teschendorff AE, Tse K, Turashvili G, Varhol R, Warren RL, Watson P, Zhao Y, Caldas C, Huntsman D, Hirst M, Marra MA, Aparicio S: Mutational evolution in a lobular breast tumour profiled at single nucleotide resolution. Nature 2009, 461(7265):809-813.

64. Ding L, Ley TJ, Larson DE, Miller CA, Koboldt DC, Welch JS, Ritchey JK, Young MA, Lamprecht T, McLellan MD, McMichael JF, Wallis JW, Lu C, Shen D, Harris CC, Dooling DJ, Fulton RS, Fulton LL, Chen K, Schmidt H, Kalicki-Veizer J, Magrini VJ, Cook L, McGrath SD, Vickery TL, Wendl MC, Heath S, Watson MA, Link DC, Tomasson MH et al: Clonal evolution in relapsed acute myeloid leukaemia revealed by whole-genome sequencing. Nature 2012, 481(7382):506-510.

doi:10.1186/1471-2407-14-982

Cite this article as: Tone et al:: Intratumoral heterogeneity in a minority of ovarian low-grade serous carcinomas. BMC Cancer 2014 14:982.

\section{Submit your next manuscript to BioMed Central and take full advantage of:}

- Convenient online submission

- Thorough peer review

- No space constraints or color figure charges

- Immediate publication on acceptance

- Inclusion in PubMed, CAS, Scopus and Google Scholar

- Research which is freely available for redistribution 